* Mestre em Direito Negocial pela Universidade Estadual de Londrina (UEL). Professor da Pontifícia Universidade Católica do Paraná (PUC -PR), Câmpus Londrina, e da Universidade Norte do Paraná (UNOPAR), Câmpus Londrina. Advogado. E-mail: henrico@henricotamiozzo. adv.br.

** Doutora e Mestre em Direito do Estado pela Pontifícia Universidade Católica de São Paulo (PUC-SP). Professora do Programa de Mestrado em Direito Negocial e do Curso de Graduação e Pós Graduação em Direito da Universidade Estadual de Londrina (UEL). Professora da Pontifícia Universidade Católica do Paraná (PUC-PR), Câmpus Londrina. E-mail: mkempferb@gmail. com.

\section{O PACTO GLOBAL E A SUSTENTABILIDADE EMPRESARIAL: POSITIVAÇÃO E EFETIVIDADE DAS DIRETRIZES E A ORDEM JURÍDICA BRASILEIRA}

\author{
THE GLOBAL PACT AND CORPORATE \\ SUSTAINABILITY: POSITIVATION, \\ EFFECTIVENESS OF GUIDELINES, AND THE \\ BRAZILIAN LEGAL SYSTEM \\ * Henrico César Tamiozzo \\ **Marlene Kempfer
}

Resumo: A visão contemporânea de negócios privados, além do legítimo direito ao lucro, precisa ser acompanhada de agir ético, para ser qualificada de empresa sustentável. A preocupação com sustentabilidade deve ser das empresas, dos consumidores e dos Estados. A partir do problema apresentado, objetiva-se o estudo de diretrizes que possibilitem às empresas relegar suas origens para fomentar a atividade sustentável. No ano de 2000 a Organização das Nações Unidas (ONU) apresentou o Pacto Global, um documento que reúne 10 princípios de cunho universalista, com o objetivo de estabelecer diretrizes para políticas e práticas de responsabilidade social empresarial. Elas podem ser reunidas em quatro grupos para tutela de direitos humanos, ambientais, do trabalho e de combate à corrupção. Foi uma importante iniciativa, porém, para efetividade depende da atuação dos Estados, das empresas e da sociedade civil na condição de consumidores conscientes, pois o Pacto não tem caráter vinculatório jurídico. A investigação deste trabalho possibilita definir que as responsabilidades dos Estados, sobretudo, são: atuação por meio normativo para imposição de condutas previstas em leis e regulamentos; atuar por meio da função administrativa para fiscalização; atuação judicial por meio de suas decisões. Para as empresas a contribuição é implementar tais diretrizes na prática empresarial independentemente do país em que atuem. Destaque-se, o importante papel do consumidor de decidir pela empresa que tem atitudes responsáveis. A partir destas premissas, a pesquisa de cunho exploratório e comparativo, volta-se ao Brasil em face do Pacto Global, no objetivo específico de avaliar (i) se a ordem jurídica contém normas que exigem condutas empresariais, conforme os princípios globais da ONU; (ii) a importância da Gestão por Valores para a as empresas; e, (iii) a participação dos consumidores para alimentar a cadeia de responsabilidade social. 
Palavras-chave: Sustentabilidade Empresarial; Ética; Pacto Global; Responsabilidade Social.

Abstract: The contemporary view of private businesses, beyond the legitimate right to profit, must be accompanied by ethical actions if they want to be classified as sustainable companies. Nevertheless, sustainability is a concern that should not only be placed on companies, but also on consumers and States. From this dilemma, one of the objectives of this research is to study the guidelines, which allows companies to leave their origins and aide sustainable activity. In 2000, the United Nations (UN) presented the Global Pact - a document that brings together ten principles with a universalistic aspect - in order to establish guidelines for policies and practices that are of corporate and social responsibility. They can be congregated into four groups: protecting the rights of humans, the environment, labor, and anti-corruption. This initiative is important, but its effectiveness depends on States' actions, companies' acts, and civil societies having, as a necessary condition, conscious consumers because the Pact has no legal-binding character. This work's investigation makes it possible to define the States responsibilities in the imposing, with normative acts, of conducts that are already outlined in laws and regulations; its actions are needed in the use of the administrative function of inspection; and judicial actions are important and made possible through its decisions. A company's contribution in this process is to implement such guidelines in business practices independently of the country in which they operate. It is also important to highlight the role of consumers in deciding if a company has met the criteria of the necessary responsible attitudes. From these premises, this exploratory and comparative research will turn its attention to Brazil. It will also relate it to the Global Pact, in particular to evaluate (i) if its laws contain the required provisions for business conducts, within the global principles of the UN; (ii) the importance of the management of a company's values; and, (iii) the consumer participation that feeds the chain of social responsibility.

Keywords: Corporate Sustainability; Ethics; Global Pact; Social Responsibility.

Como citar: TAMIOZZO, Henrico César; KEMPFER, Marlene. O pacto global e a sustentabilidade empresarial: positivação e efetividade das diretrizes e a ordem jurídica brasileira. Scientia Iuris, Londrina, v. 20, n. 1, p.114-164, abr. 2016. DOI: $10.5433 / 2178-8189.2016 v 20 n 1 p 144$. ISSN: 2178-8189. 


\section{INTRODUÇÃO}

A ação empresarial na atualidade deveria focar-se não somente no lucro mas, também, agir conforme parâmetros que compõem o discurso da sustentabilidade. Esta visão inclui, além dos valores econômicos da qualidade, eficiência e competividade, os valores morais solidariedade, equidade e confiança.

Atentando-se aos desígnios de ética e moral nas relações econômicas e de mercado é que este trabalho se propõe a estudar o papel das empresas e quais suas responsabilidades no atual panorama da globalização. Além de propriamente cumprir as leis e regulamentos atinentes à atividade econômica, será possível exigir delas a observância de parâmetros éticos e universais em promoção da sustentabilidade?

A determinação destes parâmetros a serem internalizados pelas empresas é de produção da própria iniciativa privada, dos Estados e da sociedade civil. Dentre os instrumentos universalmente aceitos, que traçam diretrizes de sustentabilidade empresarial, destaca-se nesta pesquisa o Pacto Global da Organização das Nações Unidas (ONU).

Trata-se de um programa de incentivo à atuação ética empresarial, de natureza não vinculativa, lançado oficialmente no ano de 2000. Apresenta 10 princípios que refletem desafios contemporâneos da humanidade, e são reunidos em quatro áreas: i) direitos humanos; ii) relações de trabalho; iii) meio ambiente; e, iv) combate à corrupção.

Para que a ONU alcance seus objetivos cada Estado que participa desta organização deverá internalizar estes princípios por meio, principalmente, de suas leis. Nesse sentido, o Brasil também deve se empenhar e, assim, contribuir para a prática efetiva de um ambiente negocial que gere segurança jurídica material.

A pesquisa do ordenamento jurídico brasileiro permitirá de modo específico responder se o Brasil está preparado para cumprir o compromisso de crescimento econômico com sustentabilidade, de acordo os parâmetros do Pacto Global. Face à amplitude que o tema possibilita, a análise limita-se, de modo exemplificativo, exploratório e comparativo, à atuação do Estado, das empresas e da sociedade civil.

Para as empresas que atuam em outros Estados, que ainda não positivaram os princípios referidos, internalizá-los, por meio de seus regimentos, estatutos, demonstra compromisso e uma gestão que está orientada por valores. 
É grande a responsabilidade dos consumidores para a efetividade de tais diretrizes e mesmo da ordem jurídica. O consumo consciente é seletivo. Assim, decidir contratar com empresas que têm compromisso, de fato, com a sustentabilidade alimentará a cadeia desde a matéria prima até o produto final.

É a possibilidade de um capitalismo que avança da era do progresso para o tempo do desenvolvimento com compromisso social. Muitas empresas já assim atuam e, cada vez mais, são valorizadas, pois, além de um discurso de sustentabilidade, de fato participam desta rede de gestão empresarial por valores.

\section{1 ÉTICA E A EMPRESA CONTEMPORÂNEA}

A globalização atinge praticamente todos os setores da sociedade. Para Beck (1999, p. 28), globalização significa "processos, em cujo andamento os Estados nacionais veem a sua soberania, sua identidade, suas redes de comunicação, suas chances de poder e suas orientações sofrerem a interferência cruzada de atores transnacionais.”. Para o sociólogo Giddens (1991, p. 69) é a "intensificação das relações sociais em escala mundial, que ligam localidades distantes de tal maneira que acontecimentos locais são modelados por eventos ocorrendo a muitas milhas de distância e vice-versa".

Na obra "Globalização: as consequências humanas", Bauman (1999) sintetiza ser a globalização um processo irreversível, que afeta imprevisivelmente a todos, na mesma medida e da mesma maneira. São efeitos globais sentidos pela polução, criando-se cidadãos globalizados, na medida que a globalização não diz respeito ao que desejamos fazer, mas sim o que está acontecendo a todos nós BAUMAN (1999, p. 7; 66-67).

Com as transformações que decorrem deste processo destaca-se que as empresas são atores importantes pois são fonte de novas tecnologias, ampliam as possibilidades de consumo, geram empregos, recursos públicos por meio da tributação. Assim, há relações de interdependência e para serem duradouras, precisam pautar-se por um sistema de valores e regras sustentáveis.

Domingo García-Marzá (2008, p. 23 e 28), dedica parte inicial do primeiro capítulo de sua obra para a tratar da transformação do papel social da empresa. Segundo ele, o processo de globalização trouxe aumento de poder às empresas $\mathrm{e}$, consequentemente, de sua responsabilidade, entendida como capacidade para responder às expectativas sociais nelas depositadas. Neste cenário, a disfunção entre a finalidade da empresa e o seu atuar é a principal razão da dificuldade que as empresas encontram para gerar, manter e desenvolver 
a confiança necessária no seu agir. Acrescenta que, na atual conjuntura de "crise de confiança", a solução está no agir ético empresarial para recuperar a confiança na atividade empresarial:

A ética, como resposta à dimensão moral da empresa, sempre esteve presente, mas é no atual contexto que ela se tornou clara e explícita, funcionalmente sem restrições, se assim o desejamos. Nesse sentido, uma das tarefas essenciais da ética empresarial crítica é dar justificativas ao papel da ética na empresa para evitar, na medida do possível, sua instrumentalização e, com ela, a manipulação e o engano (GARCIA-MARZÁ, 2008, p. 25):

Estudos importantes da ética voltada às relações econômico-empresariais foram desenvolvidos por Cortina (2008, p. 13-15) no sentido de enfatizar que sua recepção pelo empresariado funciona como motor de renovação social diante da geração atual que clama por uma nova ordem social. Sublinha (2008, p. 75) que há uma forte tendência, oriunda, sobretudo, da ciência econômica, em dificultar ou até mesmo impossibilitar a união da "ética" com a "empresa".

Realmente não se pode olvidar que falar em ética nos negócios, para os aplicadores da ciência econômica, pode parecer uma contradição, ou até um enfrentamento para o qual não haveria solução. Isto se explica com base na oposição dos valores eficiência e equidade, o primeiro tipicamente econômico e o segundo tipicamente moral (CORTINA, 2001, p. 263).

Advogando pela possibilidade - para não dizer, necessidade - da união entre ética e empresa, Cortina (2001, p. 265-266) comenta que a ciência econômica, propriamente, em sua essência, tem como finalidade auxiliar a vida social, ou seja, só existe para servir ao homem. Nesse sentido, compreendese que a economia não é moralmente neutra, do mesmo modo que também não é nenhuma das atividades humanas que têm desígnio social. O fim social da economia é propriamente a satisfação de necessidades humanas, e nela é possível encontrar princípios peculiares, desde eficiência até equidade, qualidade, competitividade e solidariedade. Qualquer atividade social que queira apresentar-se como legítima deve atender a critérios justos de equidade e racionalidade comunicativa.

Ao considerar o aspecto ético em suas decisões, a empresa age de forma socialmente responsável, preocupando-se com a qualidade do impacto de suas 
ações sobre as pessoas, as outras organizações, a economia e o meio ambiente. Portanto, a responsabilidade social empresarial relaciona-se intrinsicamente com o discurso ético.

Para dar sentido e efetividade ao estudo do que é de responsabilidade das empresas, nota-se ser um bom caminho a fixação de padrões e diretrizes, de bases éticas e em escala internacional, as quais responderão aos desafios da sociedade contemporânea e contribuirão para o desenvolvimento da ordem econômica sustentável.

$\mathrm{Na}$ relação intrínseca entre a universalidade ${ }^{1}$ da ética empresarial e a atualidade global das questões voltadas a ela, apresenta-se uma busca constante de diretrizes para definir as práticas e princípios básicos de comportamento que garantam e fortaleçam o tripé da sustentabilidade e a aliança de mútua confiança entre empresas, estado e sociedade (GARCÍA-MARZÁ, 2008, p. 36). A partir destes argumentos defende-se parâmetros nacionais e internacionais de ética empresarial que caminham para o desenvolvimento de empresa sustentável.

No Brasil, são exemplos os indicadores privados de responsabilidade social do Instituto Ethos de Empresas e Responsabilidade Social e as normas criadas pela Associação Brasileira de Normas Técnicas (NBR 16001). Em âmbito internacional, citam-se as propostas da Global Reporting Initiative ${ }^{2}$, as linhas e diretrizes da Organização para a Cooperação e Desenvolvimento Econômico(OCDE) sobre investimento internacional e empresas multinacionais, a International Organization for Standardizatione (ISO 26000).

\section{O PACTO GLOBAL E DIRETRIZES PARAA RESPONSABILIDADE SOCIAL DAS EMPRESAS}

A proposta do Pacto Global foi anunciada a primeira vez pelo exSecretário Geral das Nações Unidas, o ganês Kofi Annan, em 31 de janeiro de 1999 na reunião anual do Fórum Econômico Mundial (Fórum de Davos). O

\footnotetext{
"Na obra de Domingo García-Marzá cujo título é "Ética empresarial: do diálogo à confiança na empresa", quando citam-se os termos "universalidade ética" ou "universalização da ética", pretende-se falar no sentido de generalizar, difundir, propagar e uniformizar a ética, que confirme e reconheça a pluralidade da sociedade moderna, e dentro desse reconhecimento, consiga definir os mínimos morais que caracterizam o juízo prático. Assim, a universalidade da ética empresarial é a busca de padrões éticos e sustentáveis que afirmem e legitimem a atuação da atividade empresarial.

2 Organização Internacional que trabalha no campo da sustentabilidade. Seu nome, na tradução ao português, significa: "Relatório Global de Iniciativas".
} 
lançamento oficial deu-se em 26 de julho de 2000, no escritório da ONU em Nova Iorque (PACTO..., 2013a).

Trata-se de um documento composto de dez princípios reunidos em quatro áreas do Direito, quais sejam:

i) Direitos Humanos: As empresas devem apoiar e respeitar a proteção de direitos humanos reconhecidos internacionalmente; e, assegurar-se de sua não participação em violações destes direitos.

ii) Direito do Trabalho: As empresas devem apoiar a liberdade de associação e o reconhecimento efetivo do direito à negociação coletiva; $\mathrm{A}$ eliminação de todas as formas de trabalho forçado ou compulsório; A abolição efetiva do trabalho infantil; e Eliminar a discriminação no emprego.

iii) Direito de Proteção Ambiental: As empresas devem apoiar uma abordagem preventiva aos desafios ambientais; Desenvolver iniciativas para promover maior responsabilidade ambiental; e Incentivar o desenvolvimento e difusão de tecnologias ambientalmente amigáveis.

iv) Direito Penal e Administrativo Sancionatório de Combate à Corrupção, sendo esta diretriz inserida em 24 de junho de 2004: As empresas devem combater a corrupção em todas as suas formas, inclusive extorsão e propina.

É importante a participação da ONU na discussão internacional do desenvolvimento sustentável e responsabilidade das empresas, conforme destaca Estigara, Pareira e Lewis (2009, p. 45):

Ao visualizar as empresas e demais instituições como importantes atores na promoção do desenvolvimento sustentável, a ONU passou a fomentar a participação do setor privado nos esforços voltados à promoção do desenvolvimento sustentável, mediante a inserção de princípios de responsabilidade social em suas práticas. Como resultado surgiu o Pacto Global, um convite efetuado ao setor privado pelo Secretário Geral das Nações Unidas, Kofi Annan, para que juntamente com algumas agências das Nações Unidas e atores sociais contribuísse para avançar a prática da responsabilidade social corporativa, na busca de uma economia global mais sustentável e inclusiva.

O Pacto tem como objetivo mobilizar os Estados que compõem a ONU 
e a comunidade empresarial, para encorajá-las a construir uma ordem jurídica interna que positive tais princípios e adotar condutas responsáveis e ações de sustentabilidade em suas práticas de negócios, respectivamente. Esta iniciativa conta com o apoio de cinco agências da Organização das Nações Unidas - ONU, sendo elas, o Escritório do Alto Comissariado dos Direitos Humanos (OHCHR), a Organização Internacional do Trabalho (OIT), o Programa das Nações Unidas para o Meio Ambiente (PNUMA) e a Organização das Nações Unidas para o Desenvolvimento Industrial (UNIDO), lideradas pelo programa das Nações Unidas para o Desenvolvimento (PNUD) (PACTO..., 2013c).

O Pacto Global é um instrumento de livre adesão pelas empresas, organizações da sociedade civil e demais interessados, possuindo atualmente mais de 5.200 organizações signatárias, articuladas por 150 redes mundiais. Para fazer parte do programa, a empresa deverá preencher uma carta e um formulário, além de obrigar-se a informar às partes interessadas, stakeholders, acerca da adesão, emitir uma nota na imprensa para tornar o compromisso público, implementar e propagar os princípios do Pacto (PACTO..., 2013b). As empresas que aderirem ao Pacto são chamadas a publicar, anualmente, uma Comunicação de Progresso (COP), e comunicar todo ano, às partes interessadas, os progressos realizados na implementação dos dez princípios do Pacto Global.

Em dezembro de 2003 foi criado o Comitê Brasileiro do Pacto Global (CBPG), que reúne o setor privado, a sociedade civil organizada, academia e agências do Sistema das Nações Unidas no Brasil (PACTO.., 2013A). Em consulta realizada em março de 2016, a lista de signatárias do Pacto Global no Brasil era composta de 1.030 entidades (PACTO..., 2015).

Nos termos a seguir dissertados argumenta-se que o atual Estado brasileiro reúne um conjunto normativo, a partir da Constituição Federal de 1988 e normas que compõem o atual ordenamento por meio da recepção normativa, que possibilitam conviver em um ambiente de sustentabilidade conforme parâmetros da ONU.

\section{O CONJUNTO NORMATIVO BRASILEIRO E AS DIRETRIZES DO PACTO GLOBAL}

A Constituição da República Federativa do Brasil de 1988 mantém a tradição de deixar explícito o dever dos governos, das empresas e da sociedade civil, de respeitar e promover os direitos humanos, inclusive aqueles contidos nos princípios por ela adotados ou dos tratados internacionais, conforme Art. 
$5^{\circ}, \S 2^{\circ}$. Ainda, nos termos do Art. $4^{\circ}$, inciso II (BRASIL, 1988), as relações do Brasil no âmbito externo devem ser norteadas pela prevalência dos direitos humanos. A positivação dos direitos humanos em nível constitucional e infraconstitucional nas suas dimensões de individuais e coletivos, sociais e transindividuais, geram ambiente de previsibilidade tanto para relações públicas quanto privadas.

A determinação constitucional do direito fundamental à livre iniciativa, inscrita no Art. $1^{\circ}$, IV e Art. 170, parágrafo único da Carta Maior (BRASIL, 1988) cujo exercício deve submeter-se às leis, aponta a intervenção do Estado por meio normativo. Nesta modalidade interventiva e diante das diretrizes do Pacto global ora em consideração, afirma-se, que há proteção para os direitos do trabalho, do ambiente e de combate à corrupção no âmbito das relações público-empresarias.

Acrescente-se que a proteção aos direitos fundamentais é garantida pelo direito pleno de acesso à justiça (Art. $5^{\circ}$ ), devido processo legal, ampla defesa, inclusive por meio de assistência jurídica e gratuita aos que estão são considerados com insuficiência de recursos (BRASIL, 1988).

O Pacto Global com suas diretrizes destaca a necessidade de cuidados com os direitos humanos, com o trabalho humano, o ambiente e a corrupção. O Brasil reúnem atualmente valores e normas em nível constitucional e infraconstitucionais para proteger tais direitos:

a) no âmbito da valorização do trabalho humano (Art. 170) no texto constitucional (BRASIL, 1988), princípio que é fundamento para a tutela dos direitos à liberdade de associação e o reconhecimento efetivo do direito à negociação coletiva (Art. $8^{\circ}$ ); à eliminação de todas as formas de trabalho forçado ou compulsório (Art. 248); à abolição efetiva do trabalho infantil (Art. $7^{\circ}, \mathrm{XXXIII)}$; e, à eliminação de todas as formas de a discriminação no emprego (Art, $7^{\circ}$, XXX ao XXXII e XXXIV).

As regras constitucionais acima apontadas foram regulamentadas por meio de leis e atos administrativos. Entre eles, destaque-se: a Consolidação das Leis do Trabalho - CLT (BRASIL, 1943); a lei que regulamenta a condição análoga à de trabalho escravo (BRASIL, 2003); o Estatuto da Criança e do Adolescente - ECA (BRASIL, 1990a); lei que proíbe a descriminalização e práticas que limitam acesso e permanência na relação de trabalho (BRASIL, 1995).

b) no âmbito da proteção ao ambiente orientam os parâmetros do Pacto Global que as empresas devem apoiar uma abordagem preventiva aos desafios 
ambientais; Desenvolver iniciativas para promover maior responsabilidade ambiental; e, Incentivar o desenvolvimento e difusão de tecnologias ambientalmente amigáveis. Tais diretrizes, conforme o ordenamento jurídico brasileiro, estão positivadas por meio de normas que impõem condutas obrigatórias para impor condutas preventivas (licenças ambientais), punir condutas criminosas (responsabilização ambiental) e normas promocionais tais quais as que disponibilizam créditos públicos facilitados para as empresas que têm iniciativas de investimento em tecnologias que diminuam os riscos de agressão ambiental.

O marco regulatório a destacar é a Lei $\mathrm{n}^{\circ}$ 6.938/81 que institui a Política Nacional do Meio Ambiente e cria o Sistema Nacional do Meio Ambiente - SISNAMA (BRASIL, 1981), entre outras importantes regras: Lei dos Agrotóxicos (BRASIL, 1989); Lei da Política Nacional de Recursos Hídricos (BRASIL, 1997); Lei dos crimes e Infrações Ambientais (BRASIL, 1988); Estatuto da Cidade (BRASIL, 2001); Lei da Biossegurança (BRASIL, 2005); Lei da Política Nacional sobre Mudança do Clima (BRASIL, 2009); Lei da Política Nacional dos Resíduos Sólidos (BRASIL, 2010); e, o Código Florestal (BRASIL, 2012a).

c) no âmbito de combate a corrupção, inclusive de conduta de extorsão e propina e de infrações, a legislação brasileira avançou significativamente com a Lei da Empresa Limpa (BRASIL, 2013) que, nos termos de sua ementa, "responsabiliza administrativa e civil de pessoas jurídicas pela prática de atos contra a administração pública, nacional ou estrangeira". Anteriormente a esta lei já eram descritas condutas criminosas conforme, por exemplo: o Código Penal (BRASIL, 1940), que descreve as condutas de corrupção ativa (Art. 333), corrupção passiva (Art. 317) e o suborno (Art. 337-B; o crime de "lavagem" ou ocultação de bens (Art. $1^{\circ}$ ) da Lei no 9.613 (BRASIL, 1998); a tipificação da lesão ao procedimento licitatório e prejuízo ao erário público em face de contratos (Arts. 86 a 99), da Lei de Licitações (BRASIL, 1993).

As competências para intervenção do Estado sobre o domínio econômico, nos termos do Art. 174 da Constituição Federal (BRASIL, 1988), além da normativa, há a fiscalizatória. Por meio desta busca-se prevenir ou fazer cumprir as condutas que decorrem das relações do trabalho, da tutela ambiental e as antijurídicas infracionais ou criminosas tipificadas por corrupção, extorsão, propina, em consideração neste estudo. Para tanto tem-se a atuação da função administrativa e a jurisdicional do Estado. Neste sentido, conforme Bobbio (2001, p. 47) "O problema da eficácia da norma é o problema de ser ou não 
seguida pelas pessoas a quem é dirigida (os chamados destinatários da norma jurídica) e, no caso de violação, ser imposta através de meios coercitivos pela autoridade que a evocou".

A busca pela efetividade do ordenamento jurídico é um grande desafio e seu percurso será menor quando houver o reconhecimento jurídico, por seus destinatários, de sua legitimidade. Assim, se a empresa reconhece a importância e cumprir as normas que compõem o ordenamento pode-se defender que tem condutas cumpridoras de sua função social constitucional e legal.

Considerando que a ordem jurídica brasileira está em consonância com o Pacto Global e se a empresa estiver sob a jurisdição brasileira e cumpridora da sua função social estará, também, conforme as diretrizes do Pacto Global e em sintonia global com ações de sustentabilidade em seu sentido econômico, ambiental e social.

\section{ATUAÇÃO DAS EMPRESAS EM FACE DO PACTO GLOBAL}

As diretrizes do Pacto Global são importantes pois permitem avaliar as empresas que se comprometem atuar de forma sustentável. Esta avaliação pode ser realizada pelos consumidores e pela própria empresa. Para os primeiros permite escolher aquelas de quem irão comprar e, assim, contribuir para um consumo consciente. Para os empresários agir por meio de gestão que leve a construir confiança, transparência e diálogo. Este modelo é entendido por Simon L. Dolan e Salvador Garcia, como um modelo fundado em valores e, por isso, chamado de Gestão por Valores - GPV. Nesse sentido Dolan; García (2006, p. 4):

A GPV pode ser definida como uma filosofia ou prática de gestão através da qual o foco é ao mesmo tempo mantido nos valores essenciais de uma empresa e alinhado com os seus objetivos estratégicos. Esta abordagem centra-se em três domínios baseados no valor: (1) Econômico-Pragmático; (2) Ético-Social; e (3) Emocional-Desenvolvimento.

As três dimensões ou facetas de uma empresa dirigida por sistema de valores são analisadas da seguinte maneira: (1) valores Econômicos-Pragmáticos incluem valores relativos à eficácia, padrões de desempenho e disciplina, que orientam as atividades de planejamento, garantia de qualidade e contabilidade; 
(2) valores Ético-Sociais estão associados à honestidade, congruência, respeito e lealdade e orientam a forma como as pessoas se comportam em grupo; (3) valores Emocionais-Desenvolvimento relacionam-se com a confiança, liberdade e felicidade, essenciais para a criação de novas oportunidades (DOLAN; GARCÍA, 2006, p. 15).

Acima de tudo a GPV funda-se na essência da verdadeira liderança voltada aos valores humanos, vista como uma nova forma de compreender e aplicar conhecimento no campo do desenvolvimento organizacional, partindo de uma abordagem desenvolvida por psicólogos sociais e outros cientistas comportamentais de meados do século XX. Essas teorias anteriores eram conhecidas como Gestão Por Instruções (GPI), dos anos 1920, e Gestão Por Objetivos (GPO), dos anos 1960. É por meio da GPV que também se estabelece uma renovação contínua da cultura da empresa, crucial para motivar o compromisso coletivo com a criatividade da qual nasce a inovação (DOLAN; GARCÍA, 2006, p. 4; 6).

O gestor ou líder tem, basicamente, três funções: simplificar, orientar e assegurar o compromisso. Uma empresa não pode se basear na dominação, deve pautar-se pela confiança. Esta é a chave principal da gestão por valores. $\mathrm{Na}$ relação evolutiva anteriormente explicada, pode-se dizer que os chefes utilizam as instruções como ferramentas de gestão, enquanto os administradores utilizam os objetivos, contudo, por sua vez, os líderes usam os valores (DOLAN; GARCÍA, 2006, p. 5).

A confiança na empresa se constrói, especialmente, a partir de condutas que estejam conforme referenciais jurídicos ou privados fundamentados no valor econômico da eficiência (qualidade) e naqueles que fundamentam os direitos humanos, uma vez que estes têm por foco a humanização das relações e a tutela ambiental. São estes os fundamentos do Pacto Global e da ordem jurídica brasileira conforme exposto. É necessário respeitar as normas que cuidam das relações do trabalho pois sem o trabalho humano a empresa é inviável. Contribuir com inovações, tecnologias, mas, que sejam compatíveis com as normas que tutelam de modo preventivo o ambiente. Não praticar de modo direto ou se envolver com condutas de corrupção.

Além destes compromissos a empresa deve participar de redes de sustentabilidade. Nos termos do Pacto Global, assegurar-se de sua não participação em violações dos direitos humanos reconhecidos nacional e internacionalmente. As empresas devem respeitar e exigir que outras empresas, com as quais mantém negócios ou outra forma de envolvimento atuem, no 
mínimo, conforme as diretrizes do Pacto Global. A empresa que opta por uma Gestão por Valores não deve, por exemplo: negociar com empresa que emprega mão de obra escrava, infantil, discriminatória; que seja responsável por danos ambientais ou utilize matéria prima ambientalmente condenável; que tenha condenação por crimes de corrupção em suas diferentes formas de atuação ou omissão, inclusive por sonegação fiscal. Neste sentido a rede de sustentabilidade poderá contribuir significativamente para um ambiente econômico onde a ética se faz presente.

\section{A CONTRIBUiÇÃO dO PACTO GLOBAL E AS RELAÇÕES DE CONSUMO}

Embora as diretrizes do Pacto Global não tenham caráter vinculatório no âmbito jurídico são importantes para os Estados, empresas e consumidores. Com este tripé empenhado em objetivo comum, um ambiente econômico sustentável será crível. Ou seja: o Estado intervir por meio normativo, fiscalizar, para prevenir e reprimir condutas das empresas que ainda não entenderam ou não querem praticar a sua função social, inclusive, intervir por meio do incentivo com crédito público ou extrafiscalidade; as empresas em internalizar a cultura da gestão por valores; e, o consumidor ser seletivo em suas escolhas.

A maioria dos consumidores contemporâneos, em regra, estão em posição desfavorável em face do poder econômico. Este, tem presença forte de persuasão quer seja pela quantidade expressiva de produtos e serviços, o caminho do marketing a instigar o consumo e a oferta de crédito. Felizmente cresce, ainda que de modo lento, mas, contínuo, o número de consumidores que podem ser chamados de consumidores conscientes. Estes passam a tomar atitudes de resistir ao consumismo, aos produtos de obsolescência programada, e começam a avaliar a empresa por seu grau de responsabilidade social.

Avaliar a responsabilidade das empresas no que tange ao cumprimento de sua função social é muito importante. Para tanto são louváveis as contribuições das diretrizes do Pacto Global, de um ordenamento jurídico que reúna normas para possibilitar a ação do Estado ou as iniciativas de instituições que certificam as boas condutas das empresas.

A chave para abrir as portas do consumo consciente, além da educação para o consumo é importante que o valor da transparência seja positivado por meio de regras jurídicas ou pelos estatutos ou regimentos das empresas.

No caminho educacional tanto no âmbito da formação institucional 
quanto por meio do autoconhecimento deve-se considerar, por exemplo, que é preciso satisfazer as necessidades, mas impor limites às suas compras e optar por empresas que estão nesta rede de sustentabilidade. É preciso reconhecer que o capitalismo se retroalimenta pelo consumo e, até anos atrás, a isto se denominava progresso. Atualmente, este mesmo capitalismo precisa do consumo, mas, é momento de agregar ao consumo além da eficiência econômica a qualidade nas relações humanas. Em vez do progresso quer-se o desenvolvimento sustentável.

$\mathrm{O}$ valor da transparência se realiza quando o consumidor tem acesso às informações essenciais que o possibilitem escolher. Neste sentido a importância da divulgação do Pacto Global, do acesso aos cadastros públicos que informam sobre as condutas empresarias, os selos de certificações e, fundamentalmente, a organização coletiva dos consumidores.

No Brasil merece destaque o Código de Defesa do Consumidor CDC (BRASIL, 1990b) em seus Arts. $4^{\circ}$ e $6^{\circ}$ que tratam, respectivamente, da Política Nacional do Consumo e dos Direitos Básicos do Consumidor. Entre eles, destaque-se os direitos e deveres sobre o consumo adequado dos produtos e serviço, o dever de promover educação e informação sobre relações consumeristas. Inclusive, é conduta criminosa, nos termos do Art. 72 do CDC "Impedir ou dificultar o acesso do consumidor às informações que sobre ele constem em cadastros, banco de dados, fichas e registros.” (BRASIL, 1990b).

Em apoio a este fundamental direito foi aprovada a Lei $\mathrm{n}^{\mathrm{o}} 12.527$, que garante o direito a ter acesso a informações. Estas, nos termos do Art. $4^{\circ}$ dizem respeito "dados, processados ou não, que podem ser utilizados para produção e transmissão de conhecimento, contidos em qualquer meio, suporte ou formato" (BRASIL, 2011). Assim, é direito obter informações sobre empresas que foram condenadas, por exemplo, por utilizar trabalho escravo, trabalho infantil, prática de danos ambientais, corrupção. Nestes termos, nessa Lei, o Art. 21 dispõe que "Não poderá ser negado acesso à informação necessária à tutela judicial ou administrativa de direitos fundamentais" (BRASIL, 2011).

É importante registrar que para dar efetividade ao princípio da transparência e o direito à informação tem-se a Lei no $12.846 / 13$ que além de trazer normas sobre a responsabiliza administrativa e civil de pessoas jurídicas pela prática de atos contra a administração pública, nacional ou estrangeira, prevê a implementação Cadastro Nacional das Empresas Punidas, nos termos do Art. 22, com a finalidade de divulgar as sanções aplicadas às empresas no âmbito tanto do Executivo, Legislativo e Judiciário (BRASIL, 2013). Outro cadastro importante é o Cadastro Nacional de Empresas Inidôneas e Suspensas, 
que divulgam as sanções aplicadas em face de condutas de infração ou crime apurados em processos que envolvem licitações e compras governamentais. Com este panorama mínimo defende-se que a ordem jurídica brasileira reúne regras para garantir ao consumidor o acesso a dados sobre as empresas que permitem escolhas em favor das empresas que estão comprometidas com a sustentabilidade nos termos do Pacto Global.

Destaque-se que as instituições certificadores de qualidade empresarial também têm importante contribuição. Exemplificando os critérios para certificar as empresas construídos pela Associação Brasileira de Normas Técnicas (ABNT), em sua NBR 16001 publicada em 2004 e atualizada em 2012 para adaptar-se a ISO 26000 publicada em 2010. Estas normatizações estabelecem diretrizes para avaliar o sistema de gestão de responsabilidade social a todos os "tipos e portes de organizações (pequenas, médias e grandes) e de todos os setores (governo, ONG's e empresas privadas)" (INMETRO..., 2016). Entre suas diretrizes sublinhe-se o compromisso com o princípio da transparência para avaliar: o comportamento ético; o respeito pelos interesses das partes interessadas; o atendimento aos requisitos legais e outros requisitos subscritos pela organização; o respeito às normas internacionais de comportamento; o respeito aos direitos humanos e a promoção do desenvolvimento sustentável. Pode-se afirmar que tais diretrizes privadas estão em harmonia com o Pacto Global.

A empresa que se submeter a avaliação para ser certificada pode divulgar o selo de qualidade que obtiver. O consumidor informado terá, assim, mais uma fonte para fundamentar suas escolhas por ocasião das compras e contratações de serviços.

A contemporaneidade é marcada pela tecnologia da informação. Esta pode ser utilizada para organização coletiva dos consumidores, associações, fundações. Trocar informações com agilidade e de modo responsável, tem alcance para além das fronteiras. Muitas empresas atuam em diversos países e por meio dos meios de comunicação disponíveis é possível denunciar condutas que afrontam valores e regras essenciais para a convivência humana sustentável. Neste sentido, para exemplificar, consta a seguinte manchete no sítio eletrônico GreenMe "6 Multinacionais Envolvidas com Trabalho Escravo e Exploração do Infantil" (2014). Divulgar é um meio de ser uma organização combativa que contribui para estimular consumidores combativos. (FLORIOS, 2014, p. 1).

Aumentados os níveis de conhecimento e de informação do consumidor, também aumenta o seu poder de juízo crítico sobre a oportunidade e a 
conveniência da contratação. É o que se tem chamado de vontade qualificada ou consentimento esclarecido (CAVALIERI FILHO, 2011, p. 94-96). A atuação consciente do consumidor atrelada à boa-fé do fornecedor, ditada pela Gestão por Valores, deve-se fazer presente em todas as esferas do consumo, agindo no antes, durante e depois da relação de consumo.

O Brasil avança, conforme se pode aferir no Projeto de Lei n ${ }^{\circ} 3.899 / 12$, da deputada Jandira Feghali, que tramita na Câmara de Deputados Federais. Ele traz normas para uma Política Nacional de Estímulo à Produção e ao Consumo Sustentáveis. Entre importantes normas destaque-se as que tratam da competência para implementar tais políticas: "Art. $6^{\circ}$ São instrumentos da Política Nacional para o estímulo à Produção e ao Consumo Sustentáveis: I - o Selo Nacional de Produção e Consumo Sustentáveis; II - os incentivos fiscais, financeiros e creditícios, na forma da legislação pertinente [...]" (BRASIL, 2012b). Analisando o mesmo, em seu Art. $7^{\circ}$, permitirá certificação com a finalidade de desestimular práticas que não atendam aos princípios da sustentabilidade ambiental e da equidade social.

Diante das considerações apresentadas pode-se afirmar que o Brasil tem e terá, caso o projeto de lei referido seja aprovado, instrumentos que possibilitam informações para estimular o consumidor combativo.

\section{CONCLUSÃO}

O foco desta pesquisa está em analisar a importância do Pacto Global, apresentado pelo ONU, no ano de 2000, que traz diretrizes para orientar os Estados signatários desta organização, as empresas e consumidores sobre as condutas empresariais que permitem qualificar as empresas responsáveis e de atuação sustentável. Este Pacto não tem caráter jurídico vinculatório, mas, aponta para uma possibilidade de referências universalizantes, na medida em que reúnem aspectos de desafios contemporâneos: tutela dos direitos fundamentais, relações do trabalho, meio ambiente e corrupção.

Defende-se que estas diretrizes devem ser positivadas pelos Estados e, assim, terão uma ordem jurídica alinhada com a prevenção e combate, por exemplo: ao trabalho escravo, infantil, discriminatório; aos danos ambientais e à corrupção tanto nas relações econômicas privadas quanto públicas. Neste recorte, e quanto ao Brasil, pode-se afirmar que há uma ordem jurídica adequada conforme apresentado no desenvolvimento do artigo. No nível constitucional e infraconstitucional há competências para os governos 
intervirem normativamente, por meio de fiscalização e incentivo sobre o domínio econômico e positivar todos as diretrizes do Pacto Global. Defendese que não são mais necessárias leis, mas, uma atuação mais eficiente no desempenho das funções administrativas.

Quanto as empresas aponta-se que o modelo da Gestão por Valores (GPV) é um caminho que permite que elas atuem não somente motivadas por valores econômicos tais quais os da eficiência e da qualidade, mas, também, com os Ético-Sociais que estão associados à honestidade, congruência, respeito e lealdade e orientam a forma como as pessoas se comportam em grupo e valores Emocionais-Desenvolvimento relacionam-se com a confiança, liberdade e felicidade. As empresas devem atuar e exigir que outras empresas, com as quais realizam negócios, sejam parte desta rede de sustentabilidade pautada nas diretrizes do Pacto Global, mesmo que no País onde atuam a ordem jurídica não tenha positivado ou positivado parte de tais diretrizes. É importante que a empresa construa uma cultura de sustentabilidade por dever moral.

As empresas que querem ingressar e permanecer no domínio econômico devem primar por um ambiente de confiança tanto nas suas relações internas quanto externas. Neste caso, destaque-se, com os consumidores que estão a cada dia mais conscientes e combativos.

O Pacto Global é importante para despertar o consumo consciente. O consumidor tem poder de fazer suas escolhas por produtos, mercadorias, serviços e, assim, movimentar as engrenagens do capitalismo. Ao optar por realizar negócio com empresas responsáveis socialmente, satisfaz suas necessidades e contribui para manter tais empresas no mercado. Para tanto, o consumidor precisa ser educado para o consumo e ter acesso a informações, conforme dispõe o Código de Defesa do Consumidor brasileiro. Neste sentido é fundamental a divulgação do Pacto Global e dos cadastros públicos que arquivam dados sobre empresas que têm condutas reprováveis diante da ordem jurídica.

Outra fonte de informação ao consumidor são as certificações de responsabilidade social, tais quais as da Associação Brasileira de Normas Técnicas (ABNT) com sua NBR 16001 e da International Organization for Standardization (ISO) com sua ISO 26000. As normas que compõem tanto da ABNT quanto da ISO estão em harmonia com o Pacto Global. As empresas que passam pelo crivo destas instituições recebem um selo que as qualifica para o nível de empresas sustentáveis.

Finalmente, defende-se que a efetividade do Pacto Global dependerá da forte atuação dos Estados por meio de seu ordenamento jurídico e de políticas 
públicas, das empresas que têm cultural de responsabilidade social e do consumidor consciente e combativo.

\section{REFERÊNCIAS}

BAUMAN, Zygmunt. Globalização: as consequências humanas. Rio de Janeiro: Jorge Zahar Ed., 1999.

BECK, Ulrich. O que é a globalização? Equívocos do globalismo respostas à globalização. São Paulo: Paz e Terra, 1999.

BOBBIO, Norberto. Teoria da norma jurídica. Bauru: EDIPRO, 2001.

BRASIL, Constituição da República Federativa do Brasil (1988). Disponível em: $<$ http://www.planalto.gov.br/ccivil_03/constituicao/constituicao.htm>. Acesso em: 03 mar. 2016.

. Decreto-Lei $\mathrm{n}^{\circ} 2.848$, de 7 de dezembro de 1940. Disponível em: $<$ http://www.planalto.gov.br/ccivil_03/decreto-lei/del2848compilado.htm>. Acesso em: 03 mar. 2016.

. Decreto-Lei $\mathrm{n}^{\circ} 5.452$, de $1^{\circ}$ de maio de 1943. Disponível em: $<$ http://www.planalto.gov.br/ccivil_03/decreto-lei/del5452.htm>. Acesso em 03.mar.16.

. Lei $\mathrm{n}^{\circ} 6.938$, de 31 de agosto de 1981. Disponível em: <http://www. planalto.gov.br/ccivil_03/leis/L6938.htm>. Acesso em: 18 mar. 2016.

. Lei $\mathrm{n}^{\circ} 7.802$, de 11 de julho de 1989. Disponível em: $<$ http://www. planalto.gov.br/ccivil_03/leis/L7802.htm>. Acesso em: 18 mar. 2016.

. Lei no 8.069, de 13 de julho de 1990a. Disponível em: <http://www. planalto.gov.br/ccivil_03/LEIS/L8069.htm>. Acesso em: 03 mar. 2016.

. Lei $\mathrm{n}^{\circ} 8.078$, de 11 de setembro de 1990b. Disponível em: <http:// www.planalto.gov.br/ccivil_03/leis/18078.htm.>. Acesso em: 03 mar. 2016. 
. Lei n ${ }^{0} 8.666$, de 21 de junho de 1993. Disponível em:

$<$ http://www.planalto.gov.br/ccivil_03/leis/L8666cons.htm>. Acesso em: 18 mar. 2016.

. Lei $\mathrm{n}^{\circ}$ 9.029, de 13 de abril de 1995. Disponível em: <http://www. planalto.gov.br/ccivil_03/leis/19029.htm>. Acesso em: 03 mar. 2016.

. Lei $\mathrm{n}^{\circ}$ 9.433, de 8 de janeiro de 1997. Disponível em: <http://www. planalto.gov.br/ccivil_03/leis/L9433.htm>. Acesso em: 03 mar. 2016.

. Lei $\mathrm{n}^{\circ}$ 9.605, de 12 de fevereiro de 1998. Disponível em: <http:// www.planalto.gov.br/ccivil_03/leis/L9605.htm>. Acesso em: 18 mar. 2016.

. Lei no 9.613, de 3 de março de 1998. Disponível em: <http://www. planalto.gov.br/ccivil_03/leis/L9613.htm>. Acesso em: 18 mar. 2016. . Lei $\mathrm{n}^{\mathrm{o}} 10.25 \overline{7}$, de 10 de julho de 2001. Disponível em: $<$ http://www. planalto.gov.br/ccivil_03/leis/LEIS_2001/L10257.htm>. Acesso em: 18 mar. 2016.

. Lei $\mathrm{n}^{\mathrm{o}} 11.105$, de 24 de março de 2005. Disponível em: <http:// www.planalto.gov.br/ccivil_03/_ato2004-2006/2005/lei/111105.htm>. Acesso em: 18 mar. 2016.

. Lei ${ }^{\circ} 12.187$, de 29 de dezembro de 2009. Disponível em: <http:// www.planalto.gov.br/ccivil_03/_ato2007-2010/2009/lei/112187.htm>. Acesso em: 18 mar. 2016.

. Lei $\mathrm{n}^{\mathrm{o}} 12.305$, de 2 de agosto de 2010. Disponível em: $<$ http://www. planalto.gov.br/ccivil_03/_ato2007-2010/2010/lei/112305.htm>. Acesso em: 18 mar. 2016.

. Lei $\mathrm{n}^{\mathrm{o}}$ 12.527, de 18 de novembro de 2011. Disponível em: <http://www.planalto.gov.br/ccivil_03/_ato2011-2014/2011/lei/112527.htm Acesso em: 18 mar. 2016.

. Lei $\mathrm{n}^{\mathrm{o}}$ 12.651, de 25 de maio de 2012. Disponível em: <http://www. 
planalto.gov.br/ccivil_03/_ato2011-2014/2012/lei/112651.htm>. Acesso em: 18 mar. 2016.

. Lei $\mathrm{n}^{\mathrm{o}} 12.846$, de $1^{\mathrm{o}}$ de agosto de 2013. Disponível em: <http:// www.planalto.gov.br/ccivil_03/_Ato2011-2014/2013/Lei/L12846.htm>. Acesso em: 18 mar. 2016.

. Projeto de Lei $N^{0} 3.899$, de 16 de maio de 2012a.

Disponível em: < http:/www.camara.gov.br/proposicoesWeb/prop_ mostrarintegra;jsessionid=4689B3C8B9726D63BFF41B5B603BE5CF. proposicoesWeb2 codteor $=994092 \&$ filename $=P L+3899 / 2012>$. Acesso em 03.mar.16.

. Projeto de Lei $\mathrm{n}^{\mathrm{o}} 3899$, de 22 de maio de 2012b.

Disponível em: <http://www.camara.gov.br/proposicoesWeb/ fichadetramitacao?idProposicao=545304> . Acesso em: 18 mar. 2016.

CAVALIERI FILHO, Sergio. Programa de direito do consumidor. São Paulo: Atlas, 2011.

CORTINA, Adela. Ética aplicada y democracia radical. Madri: Tecnos, 2001.

. Ética de la Empresa: claves para una nueva cultura empresarial. Madrid: Trotta, 2008.

DOLAN, Simon L.; GARCIA, Salvador. Gestão por valores. Porto: BioRumo, 2006.

ESTIGARA, Adriana; PEREIRA, Reni; LEWIS, Sandra A. L. Barbon. Responsabilidade social e incentivos fiscais. São Paulo: Atlas, 2009.

FLORIOS, Daia. Multinacionais envolvidas com trabalho escravo e exploração infantil. 2014. Disponível em: < https://www.greenme.com.br/ viver/trabalho-e-escritorio/126-6-multinacionais-envolvidas-com-trabalhoescravo-e-exploracao-infantil>. Acesso em: 03 mar.16. 
GARCÍA-MARZÁ, Domingo. Ética empresarial: do diálogo à confiança na empresa. Pelotas, Educat, 2008.

GIDDENS, Anthony. As consequências da modernidade. São Paulo: Editora Unesp, 1991.

INSTRUÇÃO NORMATIVA N. 91, de 05 de outubro de 2011. Disponível em: <http://portal.mte.gov.br/data/ files/8A7C812D32DC09BB0132DFD134F77441/in_20111005_91.pdf >. Acesso em: 25 ago. 2015.

INMETRO. A norma nacional: ABNT NBR 16001. 2004.Disponível em: $<$ http://www.inmetro.gov.br/qualidade/responsabilidade_social/norma_ nacional.asp $>$. Acesso em: 03 mar.16.

PACTO GLOBAL REDE BRASILEIRA. Histórico. 2013. Disponível em: $<$ http://www.pactoglobal.org.br/artigo/63/Historico>. Acesso em: 03 mar. 2016.

PACTO GLOBAL REDE BRASILEIRA . Lista de signatários. 2015. Disponível em: $<$ http://www.pactoglobal.org.br/artigo/64/Lista-deSignatarios $>$. Acesso em 03 mar. 2016.

PACTO GLOBAL REDE BRASILEIRA. Objetivos. 2013. Disponível em: $<$ http://www.pactoglobal.org.br/artigo/57/Objetivos $>$. Acesso em: 03 mar. 2016.

PACTO GLOBAL REDE BRASILEIRA . O que é? 2013. Disponível em $<$ http://www.pactoglobal.org.br/artigo/70/O-que-eh>. Acesso em 03 mar. 2016.

Como citar: TAMIOZZO, Henrico César; KEMPFER, Marlene. O pacto global e a sustentabilidade empresarial: positivação e efetividade das diretrizes e a ordem jurídica brasileira. Scientia Iuris, Londrina, v. 20, n. 1, p.114-164, abr. 2016. DOI: 10.5433/2178-8189.2016v20n1p144. ISSN: $2178-8189$. 
Submetido em 08/10/2015

Aprovado em 18/03/2016 